\title{
Clinical researches
}

\section{НЕЗАЛЕЖНІ ПРЕДИКТОРИ ПОЗИТИВНОЇ ВІДПОВІДІ НА ІМПЛАНТАЦЮЮ ЕЛЕКТРОКАРДІОСТИМУЛЯТОРА У ПАЦІЕНТІВ ІЗ ХРОНІЧНОЮ СЕРЦЕВОЮ НЕДОСТАТНІСТЮ}

\author{
Бринза М. С., Вороненко О. С.
}

Вступ. Протягом останніх десятирічь реєструють збільшення смертності від хронічної серцевої недостатності, для лікування якої може застосовуватись імплантація електрокардіостимулятора. Імплантовані електрокардіостимулятори розширюють можливості медикаментозної терапії, але вимагають професійного моніторингу і титрування призначаємих лікарських засобів.

Мета. Визначити та оцінити незалежні предиктори позитивної відповіді на імплантацію постійного електрокардіостимулятора у пацієнтів із хронічною серцевою недостатністю в залежності від наявності цукрового діабету 2-го типу.

Матеріали та методи. Обстежено 203 хворих на хронічну серцеву недостатність, які перебували на стаціонарному лікуванні та амбулаторному обстеженні у відділенні ультразвукової та клінікоінструментальної діагностики і мініінвазивних втручань ДУ «Інститут загальної та невідкладної хірургії імені В. Т. Зайцева НАМН України» та мали обгрунтовані покази для імплантації електрокардіостимулятора. Імплантація проведена 102 хворим на хронічну серцеву недостатність із супутнім цукровим діабетом 2-го типу, які склали основну або 1-у групу; серед представників цієї групи було 52 чоловіка, середній вік обстежених учасників складав $(67,7 \pm 8,3)$ років. В якості контрольної групи обрані пацієнти 3 хронічною серцевою недостатністю, котрим також проведено імплантування електрокардіостимулятора, але без коморбідного цукрового діабету ( $\mathrm{n}=101)$.

Результати. Встановлено, що жіноча стать достовірно асоціювалася із відсутністю відповіді на імплантацію електрокардіостимулятора. Майже на встановленому рівні достовірності визначився вплив режиму електрокардіостимулятора, який визначив асоціацію режиму DDDR із розвитком відповіді на лікування. Цікавим $є$ той факт, що пацієнти із АВ-блокадою Мобітц II мали достовірно вищі шанси відповісти на імплантацію електрокардіостимулятора. Аналізуючи клінічні форми IXC, встановлено, що порівняно із пацієнтами без IXC, наявність стабільної стенокардії достовірно збільшувала шанси не відповісти на імплантацію. Подібний, але більш сильний вплив, чинила наявність кардіосклерозу будь-якого генезу. Дуже вагомий незалежний вплив на відсутність відповіді на ЕКС чинив постінфарктний кардіосклероз, тоді як наявність артеріальної гіпертензії та іiї стадії не мали такої здатності.

Висновки. Отримані незалежні предиктори дозволяють провести ранню оцінку успішності проведення електрокардіостимуляції у пацієнтів із ХCH, що може попередити небажані наслідки чи провести попередню профілактику з метою покращення відповіді на імплантацію ЕКС у таких пацієнтів.

КЛЮЧОВІ СЛОВА: хронічна серцева недостатність, імплантація електрокардіостимулятора, цукровий діабет 2-го типу

\section{ІНФОРМАЦІЯ ПРО АВТОРІВ}

Бринза Марія Сергіївна, к.мед.н., доцент, завідувач кафедри пропедевтики внутрішньої медицини і фізичної реабілітації Харківського національного університету імені В. Н. Каразіна, просп. Ак. Курчатова, 29, Харків, Україна, 61108, e-mail: maltsevamariya@gmail.com, https://orcid.org/0000-0002-9474-198X

Вороненко Олена Сергіївна, асистент кафедри пропедевтики внутрішньої медицини і фізичної реабілітації Харківського національного університету імені В. Н. Каразіна, проспект Ак. Курчатова, 29, Харків, Україна, 61108, e-mail: esvoronenko@gmail.com, ORCID ID: https://orcid.org/0000-0002-9474-198X

\section{ВСТУП}

Протягом останніх десятирічь реєструють збільшення смертності від хронічної серцевої недостатності (XCH),

(ㄷ) Бринза М. С., Вороненко О. С., 2021 для лікування якої може застосовуватись імплантація електрокардіостимулятора.

Вважається, що від $1 \%$ до $5 \%$ від загальної чисельності населення в Європі страждають на хронічну серцеву 
недостатність [1]. В межах України ХСН відзначена у $6 \%$ населення країни. Епідеміологічні дані підтверджують, що близько половини пацієнтів $3 \mathrm{XCH} \epsilon$ жінки, і близько $40 \%$ - чоловіки.

Імплантовані електрокардіостимулятори (ЕКС) розширюють можливості медикаментозної терапії, але вимагають професійного моніторингу i титрування призначаємих лікарських засобів [2, 3], що підвищує їх ефективність і знижує ризик госпіталізації і смерті від будь-якої причини [4] завдяки більш результативному зворотньому ремоделюванню камер, поліпшенню їх систолічної та діастолічної функцій, зниженню мітральної регургітації та ін. [5] 3 припиненням прогресування XCH у багатьох хворих.

\section{МАТЕРІАЛИ Й МЕТОДИ}

Обстежено 203 хворих на XСH (за Міжнародною класифікацію хвороб ХІ перегляду [6]), які перебували на стаціонарному лікуванні та амбулаторному обстеженні у відділенні ультразвукової та клініко-інструментальної діагностики і мініінвазивних втручань ДУ «Інститут загальної та невідкладної хірургії ім. В. Т. Зайцева НАМН України» та мали обгрунтовані покази для імплантації ЕКС.

Показання для імплантації ЕКС на тлі $\mathrm{XCH}$ формулювали згідно діючих рекомендацій ACC/AHA та ESC [7].

Критеріями виключення виявилися: вік пацієнтів старше 90 років, особи, які нещодавно (протягом найближчих 90 діб) перенесли інфаркт міокарда або мали важку декомпенсацію серцевої недостатності $(\mathrm{CH})$, страждали на цукровий діабет (ЦД) 1-го типу або приймали препарати інсуліну 3 метою компенсації рівня глікемії (так званий вторинний інсулін-залежний ЦД 2-го типу).

Пацієнти 3 імплантованими ЕКС отримували медикаментозну терапію 3 метою корекції основної та коморбідної патології. Вибір препарату, підбір необхідної дози та тривалості фармакотерапії визначали на підставі діючих європейських та вітчизняних рекомендацій щодо імплантування ЕКС [5], лікування ХCH [8, 9], артеріальної гіпертензії (АГ) [10], фібриляції передсердь (ФП) [11].

Пацієнтам імплантували двокамерний ЕКС (Sorin (Італія), Vitatron (Голандія), Medtronic (Ірландія), St. Jude Medical (США)) згідно стандартної методики [5]; під час імплантації положення електродів у правому передсерді та шлуночку контролювали за допомогою флюороскопії. Стимуляцію проводили у двох режимах: використовували двокамерну стимуляцію передсердь та шлуночків 3 детекцією їх спонтанної активності та наявністю інгібуючого та критичного механізму управління роботи EKC (DDD), a також двокамерну частотно-адаптивну електрокардіостимуляцію (DDDR). Ефективність втручання оцінювали через 12 місяців за результатами транс торакального ультразвукового обстеження: при підвищенні показника кінцевого діастолічного об'єму лівого шлуночка (КДОЛШ) на $15 \%$ операцію вважали ефективною, тоді як хворих, які не продемонстрували відповідного регресу зазначеного показника, класифікували як осіб, що не відповіли на імплантацію.

Статистична обробка. Для характеристики центральної тенденції та варіабельності кількісних ознак (безперервних чи інтервальних) визначали середне значення (M) та стандартне квадратичне відхилення (SD, $\sigma)$. Результат надавали у вигляді $\mathrm{M} \pm \mathrm{SD}$. Вірогідність відмінностей кількісних показників в двох непов'язаних групах визначали за допомогою U-тесту Мана-Уітні. Визначення асоціацій показників із біноміальною залежною змінною було проведено із використанням множинного логістичного регресійного аналізу із розрахунком коефіцієнтів $\beta$, стандартизованих коефіцієнтів $\beta$ (відношення шансів (ВШ) та їх $95 \%$ довірчих інтервалів (ДІ). Для отриманих моделей було додатково розраховано показники чутливості та специфічності. Під чутливістю розуміли частку коректно ідентифікованих позитивних результатів, які були вірно визначені моделлю. Під специфічністю розуміли частку коректно ідентифікованих негативних результатів, які були вірно визначені моделлю. Результат надавали у відсотках. Для проведення вищезазначених розрахунків 
було пакет статистичних програм IBM SPSS 25.0 для Windows.

\section{РЕЗУЛЬТАТИ ТА ОБГОВОРЕННЯ}

Імплантація ЕКС проведена 102 хворим на ХCH із супутнім ЦД 2-го типу, які склали основну або 1-у групу; серед представників цієї групи було 52 чоловіка, середній вік обстежених учасників складав $(67,7 \pm 8,3)$ років. В якості контрольної групи обрані пацієнти з ХCH, яким також проведена імплантація ЕКС, але без коморбідного ЦД $(\mathrm{n}=101)$. В контрольній групі невірогідно переважали чоловіки (63 особи), середній вік - 68,3 $\pm 7,8$ років. Міжгрупова різниця щодо гендерновікового складу сформованих груп була не вірогідною $\left(\chi^{2}=2,684, \mathrm{p}=0,101\right)$.

Проаналізував показники індексу маси тіла (IMT), ми встановили, що в сформованій когорті тільки невелика кількість хворих мала нормальну масу тіла: $(36,9 \pm 4,8 \%)$ осіб в основній групі та

$(40,6 \pm 4,9 \%)$ осіб у контрольній. Кількість учасників основної групи із надмірною масою тіла $(34,9 \pm 4,7 \%)$, ожирінням 1-го $(11,7 \pm 3,1 \%), \quad 2$-го $(11,7 \pm 3,1 \%)$ та 3 -го ступенів $(4,8 \pm 2,1 \%)$ достовірно не відрізнялась від аналогічних показників у пацієнтів контрольної групи (відповідно, $(39,6 \pm 4,8 \%), \quad(8,9 \pm 2,8 \%)$, $(8,9 \pm 2,8 \%) \quad$ та $(1,9 \pm 1,3 \%) ; \quad$ в усіх випадках $\mathrm{p}>0,05)$.

Аналіз особливостей госпіталізації дозволив 3'ясувати, що представникам основної та контрольної групи імплантація ЕКС проводилась в ургентних умовах: відповідно, 75,5\% та 75,2\%. Тільки невелика кількість хворих надходила у хірургічний стаціонар планово: в основній групі таких пацієнтів було 24,5\%, в контролі - 24,8 \% (міжгрупова різниця невірогідна; $\mathrm{p}>0,05)$. Таким чином, сформовані групи були співставними за гендерно-віковими, антропометричними показниками та анамнестичними даними.

Таблиця 1

Зв'язок гендерно-антропометричних, анамнестичних даних та результатів ЕКГ перед операцією із відповіддю на імплантацію ЕКС у пацієнтів із ХСН

\begin{tabular}{|c|c|c|c|c|}
\hline \multirow[b]{2}{*}{ Показники } & \multirow[b]{2}{*}{$\mathrm{p}$} & \multirow[b]{2}{*}{ ВШ } & \multicolumn{2}{|c|}{95 \% ДІ для ВШ } \\
\hline & & & $\begin{array}{c}\text { Нижня } \\
\text { межа }\end{array}$ & $\begin{array}{c}\text { Верхня } \\
\text { межа }\end{array}$ \\
\hline Жіноча стать & 0,011 & 3,020 & 1,290 & 7,066 \\
\hline Режим EKC (DDDR) & 0,091 & 0,468 & 0,194 & 1,128 \\
\hline АВ-блокада відсутня & 0,088 & \multicolumn{3}{|c|}{ Референсна група } \\
\hline АВ-блокада Мобітц II & 0,031 & 0,325 & 0,117 & 0,905 \\
\hline Повна АВ-блокада & 0,626 & 0,769 & 0,267 & 2,213 \\
\hline ІХС немає & 0,064 & \multicolumn{3}{|c|}{ Референсна група } \\
\hline IXC стабільна стенокардія & 0,024 & 4,511 & 1,218 & 16,706 \\
\hline IXC кардіосклероз & 0,038 & 5,299 & 1,096 & 25,629 \\
\hline Постінфарктний кардіосклероз & 0,005 & 11,285 & 2,073 & 61,445 \\
\hline Немає $A \Gamma$ & 0,076 & \multicolumn{3}{|c|}{ Референсна група } \\
\hline АГ І стадії & 0,451 & 1,626 & 0,460 & 5,752 \\
\hline АГ II стадії & 0,121 & 0,376 & 0,109 & 1,295 \\
\hline АГ III стадії & 0,195 & 0,322 & 0,058 & 1,784 \\
\hline Константа & 0,003 & 0,092 & & \\
\hline
\end{tabular}

Як можна бачити 3 табл. 1, сукупна оцінка клініко-анамнестичних та інструментальних показників виявила низку незалежних предикторів відповіді на імплантацію електрокардіостимулятора у обстежених пацієнтів. Предиктори включали в себе стать пацієнтів, режим роботи ЕКС, наявність чи відсутність АВблокади різного ступеню, наявність та тип ішемічної хвороби серця (IXC), наявність та стадію артеріальної гіпертензії та анамнез постінфарктного кардіосклерозу.

Так, жіноча стать достовірно ( $\mathrm{p}=0,011)$ асоціювалася із відсутністю відповіді: 
ВШ = 3,020 [95 \% ДІ 1,290-7,066]. Майже на встановленому рівні достовірності визначився вплив режиму ЕКС, який визначив асоціацію режиму DDDR із розвитком відповіді на лікування: ВШ $=0,468$ [95 \% ДІ $\quad 0,194-1,128]$, $(\mathrm{p}=0,091)$.

Порівняно із відсутністю АВ-блокади, пацієнти із АВ-блокадою Мобітц II мали достовірно вищі шанси відповісти на імплантацію ЕКС: $\quad$ ВШ $=0,325$ [95\% ДІ $0,117-0,905],(\mathrm{p}=0,031)$. Варто додати, що наявність повної АВ-блокади достовірно не впливала на результативність ЕКС, порівняно із відсутністю даного порушення провідності (ВШ $=0,769$ [95 \% ДІ 0,267-2,213], $\mathrm{p}=0,626)$ (рис. 1 , табл. 1$)$.

Аналізуючи клінічні форми IXC (табл. 1), встановлено, що порівняно із пацієнтами без IXC, наявність стабільної стенокардії достовірно збільшувала шанси не відповісти на імплантацію ЕКС: ВШ $=4,511$ [95 \% ДІ 1,218-16,706], $(\mathrm{p}=0,024)$. Подібний, але більш сильний вплив, чинила наявність кардіосклерозу будь-якого генезу: ВШ $=5,299$ [95 \% ДІ 1,096-25,629], $(\mathrm{p}=0,038)$. Дуже вагомий незалежний вплив на відсутність відповіді на ЕКС чинив постінфарктний кардіосклероз: $\quad$ ВШ $=11,285$ [95\% ДI $2,073-61,445], \quad(p=0,005), \quad$ тоді наявність АГ та іiї стадії не мали такого впливу.

Варто зазначити, що чутливість та специфічність даної моделі (табл. 1) склали, відповідно 85,4 \% та 17,4\%.

На рис. 1 проілюстровано достовірний вплив жіночої статі на зниження шансів відповісти на імплантацію ЕКС. Варто зазначити, що усі види IXC достовірно суттєво знижували шанс відповісти на встановлення ЕКС.

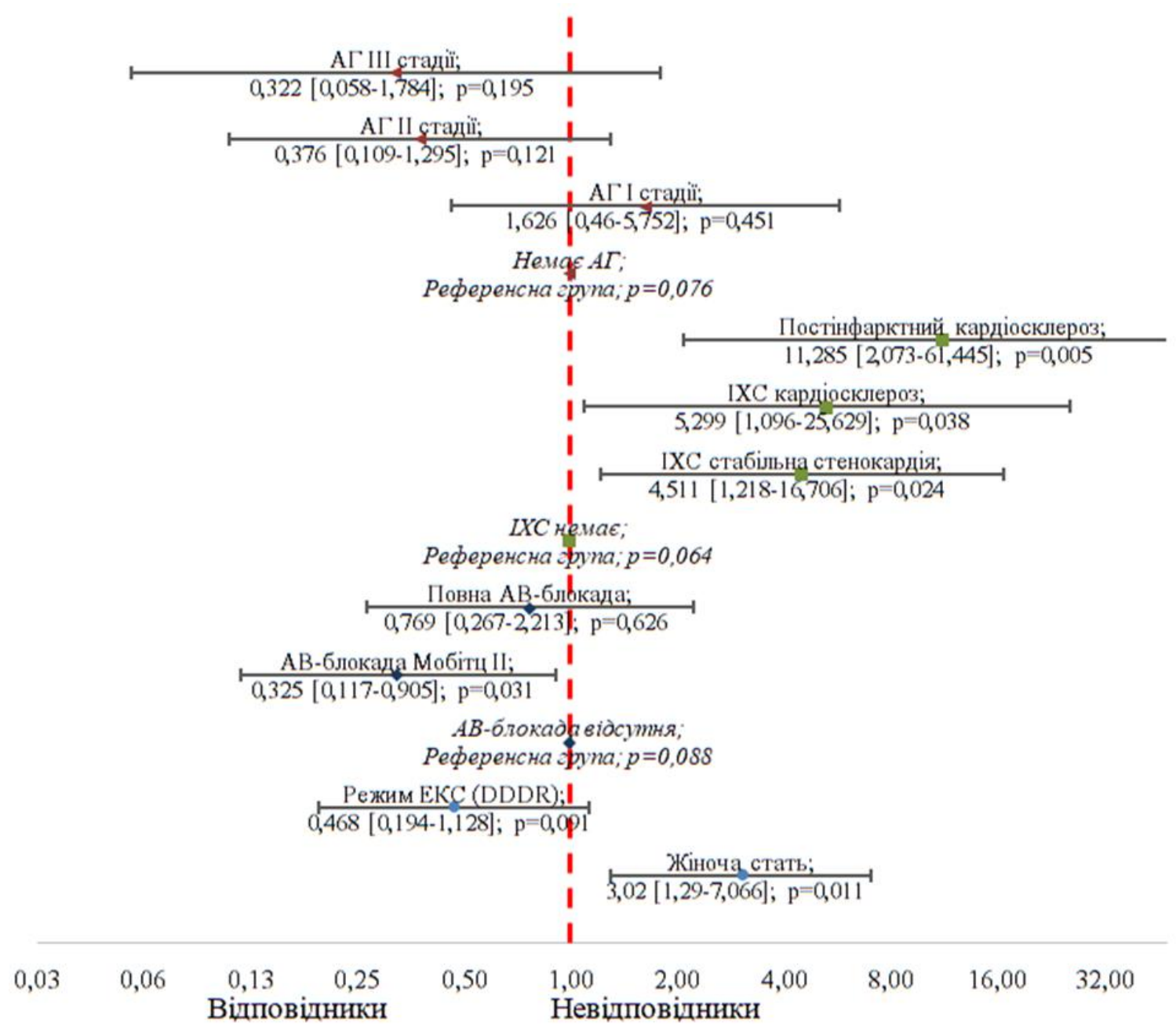

Рис. 1. Графічне зображення шансів відповіді на імплантацію ЕКС залежно від додаткових клініко-анамнестичних факторів, ВШ [95 \% ДІ]. 


\section{ВИСНОВКИ}

1. У хворих обох груп було встановлено достовірну асоціацію жіночої статі зі зниженням шансу відповіді на імплантацію ЕКС.

2. Більш фізіологічний режим електрокардіостимуляції був асоційований iз розвитком відповіді на імплантацію ЕКС, проте показник виявився на межі встановленого рівня достовірності, що свідчить про наявність тенденції.

3. Наявність різних форм IXC та постінфарктного кардіосклерозу достовірно суттєво знижувало шанси на успіх електрокардіостимуляції у обстежених пацієнтів.

4. Порівняно із відсутністю порушень атріо-вентрикулярної провідності, АВблокада типу Мобітц II асоціювалася майже із $75 \%$ збільшенням шансу на відповідь на електрокардіостимуляцію.
5. Наявність та стадія АГ достовірно не чинили впливу на успішність даного лікувального методу.

6. Отримані незалежні предиктори дозволяють провести ранню оцінку успішності проведення електрокардіостимуляції у пацієнтів із $\mathrm{XCH}$, що може попередити небажані наслідки чи провести попередню профілактику 3 метою покращення відповіді на імплантацію ЕКС у таких пацієнтів.

\section{ПЕРСПЕКТИВИ ДОСЛІДЖЕНЬ}

Перспективою подальших досліджень $\epsilon$ збільшення вибірки пацієнтів, включення в аналіз пацієнтів із іншими морфофункціональними порушеннями діяльності серця та включення до аналізу пацієнтів із низкою супутніх захворювань 3 метою оцінки їх незалежного впливу на ефективність імплантації ЕКС.

\section{СПИСОК ЛІТЕРАТУРИ}

1. Населення України за 2019 рік. Демографічний щорічник / Державна служба статистики України. 2020 Окт 19. http://database.ukrcensus.gov.ua/PXWEB2007/ukr/publ_new1/index.asp

2. Егоров Д. Диагностика и лечение пациентов с имплантированными антиаритмическими устройствами. 2005 Апр. https://webmed.irkutsk.ru/doc/pdf/vnoa.pdf

3. Iqbal J, Francis L, Reid J. Quality of life in patients with chronic heart failure and their carers: a 3-year follow-up study assessinghospitalization and mortality. 2010 Sep 12 (9): 1002-8. https://doi.org/10.1093/eurjhf/hfq114.

4. Gould P. Clinical treatment regimens for chronic heart failure: a review. 2002 Nov 3(11):1569-76. https://doi.org/10.1517/14656566.3.11.1569

5. Lang R, Badano L, Mor-Avi V, et al. Recommendations for cardiac chamber quantification by echocardiography in adults: an update from the American Society of Echocardiography and the European Association of Cardiovascular Imaging. 2015 Jan 28(1):1-39. https://doi.org/10.1016/j.echo.2014.10.003

6. Ponikowski P, Voors A, Anker S, et al. 2016 ESC Guidelines for the diagnosis and treatment of acute and chronic heart failure: The Task Force for the diagnosis and treatment of acute and chronic heart failure of the European Society of Cardiology (ESC)Developed with the special contribution of the Heart Failure Association (HFA) of the ESC [published correction appears in Eur Heart J. 2016 Dec 30;:]. 2016 Jul 37 (27): 2129-2200. https://doi.org/10.1093/eurheartj/ehw128

7. Galderisi M, Cosyns B, Edvardsen T, et al. Standardization of adult transthoracic echocardiography reporting in agreement with recent chamber quantification, diastolic function, and heart valve disease recommendations: an expert consensus document of the European Association of Cardiovascular Imaging. 2017 Dec 18 (12): 1301-1310. https://doi.org/10.1093/ehjci/jex244

8. Yancy C, Jessup M, Bozkurt B, et al. 2017 ACC/AHA/HFSA Focused Update of the 2013 ACCF/AHA Guideline for the Management of Heart Failure: A Report of the American College of Cardiology/American Heart Association Task Force on Clinical Practice Guidelines and the Heart Failure Society of America. Circulation. 2017 Aug 136 (6): 137-161. https://doi.org/10.1161/CIR.0000000000000509

9. Воронков Л, Березин О, Амосова К. Рекомендації Асоціації кардіологів України з діагностики та лікування хронічної серцевої недостатності. Серцева недостатність та коморбідні стани. 2020 Oct (27):1-33.

https://www.researchgate.net/publication/345385454_Serceva_nedostatnist_u_hvorih_na_cukrovij_diabet _Rekomendacii_Vseukrainskoi_asociacii_kardiologiv_Ukraini_ta_Vseukrainskoi_asociacii_fahivciv_iz_s ercevoi_nedostatnosti 
10 The Task Force for the management of arterial hypertension of the European Society of Cardiology (ESC) and the European Society of Hypertension (ESH). 2018 Oct; 36 (10): 1953-2041. https://doi.org/10.1097/HJH.0000000000001940

11. Діагностика та лікування фібриляції передсердь. Рекомендації робочої групи по порушенням серцевого ритму Асоціації кардіологів України. 2011. Електроний документ. Режим доступу: https://strazhesko.org.ua/upload/2014/02/20/book_ukr_-10-2011-_preview.pdf

\section{REFERENCES}

1. Naselennia Ukrainy za 2019 rik. Demohrafichnyi shchorichnyk / Derzhavna sluzhba statystyky Ukrainy. 2020 Oct 19. http://database.ukrcensus.gov.ua/PXWEB2007/ukr/publ_new1/index.asp

2. Egorov D. Diagnostika i lechenie patsientov s implantirovannyimi antiaritmicheskimi ustroystvami. 2005 Apr. https://webmed.irkutsk.ru/doc/pdf/vnoa.pdf

3. .Iqbal J, Francis L, Reid J. Quality of life in patients with chronic heart failure and their carers: a 3-year follow-up study assessinghospitalization and mortality. 2010 Sep 12 (9): 1002-8. https://doi.org/10.1093/eurjhf/hfq114.

4. Gould P. Clinical treatment regimens for chronic heart failure: a review. 2002 Nov 3(11):1569-76. https://doi.org/10.1517/14656566.3.11.1569

5. Lang R, Badano L, Mor-Avi V, et al. Recommendations for cardiac chamber quantification by echocardiography in adults: an update from the American Society of Echocardiography and the European Association of Cardiovascular Imaging. 2015 Jan 28 (1): 1-39. https://doi.org/10.1016/j.echo.2014.10.003

6. Ponikowski P, Voors A, Anker S, et al. 2016 ESC Guidelines for the diagnosis and treatment of acute and chronic heart failure: The Task Force for the diagnosis and treatment of acute and chronic heart failure of the European Society of Cardiology (ESC)Developed with the special contribution of the Heart Failure Association (HFA) of the ESC [published correction appears in Eur Heart J. 2016 Dec 30;:]. 2016 Jul 37 (27): 2129-2200. https://doi.org/10.1093/eurheartj/ehw128

7. Galderisi M, Cosyns B, Edvardsen T, et al. Standardization of adult transthoracic echocardiography reporting in agreement with recent chamber quantification, diastolic function, and heart valve disease recommendations: an expert consensus document of the European Association of Cardiovascular Imaging. 2017 Dec 18(12):1301-1310. https://doi.org/10.1093/ehjci/jex244

8. Yancy C, Jessup M, Bozkurt B, et al. 2017 ACC/AHA/HFSA Focused Update of the 2013 ACCF/AHA Guideline for the Management of Heart Failure: A Report of the American College of Cardiology/American Heart Association Task Force on Clinical Practice Guidelines and the Heart Failure Society of America. Circulation. 2017 Aug $136 \quad$ (6): 137-161. https://doi.org/10.1161/CIR.0000000000000509

9. Voronkov L, Berezyn O, Amosova K. Rekomendatsii Asotsiatsii kardiolohiv Ukrainy z diahnostyky ta likuvannia khronichnoi sertsevoi nedostatnosti. Sertseva nedostatnist ta komorbidni stany. 2020 Oct (27):1-33.

https://www.researchgate.net/publication/345385454_Serceva_nedostatnist_u_hvorih_na_cukrovij_diabet _Rekomendacii_Vseukrainskoi_asociacii_kardiologiv_Ukraini_ta_Vseukrainskoi_asociacii_fahivciv_iz_s ercevoi_nedostatnosti

10 The Task Force for the management of arterial hypertension of the European Society of Cardiology (ESC) and the European Society of Hypertension (ESH). 2018 Oct; 36 (10): 1953-2041. https://doi.org/10.1097/HJH.0000000000001940

11. Diahnostyka ta likuvannia fibryliatsii peredserd. Rekomendatsii robochoi hrupy po porushenniam sertsevoho rytmu Asotsiatsii kardiolohiv Ukrainy. 2011. Elektronyi dokument. https://strazhesko.org.ua/upload/2014/02/20/book_ukr_-10-2011-_preview.pdf

\section{INDEPENDENT PREDICTORS OF A POSITIVE RESPONSE TO PACEMAKER IMPLANTATION IN PATIENTS WITH CHRONIC HEART FAILURE}

Brynza M. S., Voronenko O. S.

Introduction. Over the past decades, an increase in mortality from chronic heart failure has been recorded, for the treatment of which the implantation of a pacemaker can be used. The implanted pacemaker expands the possibilities of drug therapy, but requires professional monitoring and titration of the drugs used.

Purpose. To determine and evaluate independent predictors of a positive response to permanent pacemaker implantation in patients with chronic heart failure, depending on the presence of type 2 diabetes. 
Materials and methods. Examined 203 patients with CHF who were inpatient treatment and outpatient examination in the department of ultrasound and clinical and instrumental diagnostics and minimally invasive interventions of the State Institution «V. T. Zaycev Institute of General and Urgent Surgery» and had reasonable indications for implantation of pacemaker. Pacemaker implantation was performed in 102 patients with chronic heart failure with concomitant type 2 diabetes, which made up the main or first group; among the representatives of this group there were 52 people, the average age of the surveyed participants was $(67.7 \pm$ 8.3) years. Patients with CHF who also underwent pacemaker implantation, but without comorbid diabetes mellitus $(n=101)$ were selected as a control group.

Results. It was found that the female sex was significantly associated with the absence of response to pacemaker implantation. The influence of the pacemaker regime was determined almost at the established level of confidence, which determined the associations of the DDDR regime with the development of response to treatment. Patients with AV block Mobitz II had significantly higher chances of responding to pacemaker implantation. Analyzing the clinical forms of coronary artery disease, it was found that, compared with patients without coronary artery disease, the presence of stable angina pectoris significantly increased the chances of not responding to implantation. Stronger influence was exerted by the presence of cardiosclerosis of any genesis.

Findings. The obtained independent predictors allow an early assessment of the success of cardiac pacing in patients with $\mathrm{CHF}$, which can prevent unwanted consequences or conduct preliminary prophylaxis in order to improve the response to pacemaker implantation in such patients.

KEY WORDS: chronic heart failure, pacemaker implantation, type 2 diabetes mellitus

\section{INFORMATION ABOUT AUTHORS}

Mariia Brynza, MD, PhD, Associate professor of the Department of Propedeutics of Internal Medicine and Physical Rehabilitation of Kharkiv National University of V. N. Karazin. Prosp. Ak. Kurchatova, 29, Kharkiv, Ukraine, 61108, email: maltsevamariya@gmail.com,_ORCID ID: https://orcid.org/0000-0002-8260-3600

Olena Voronenko, Assistant Professor of the Department of Propedeutics of Internal Medicine and Physical Rehabilitation of Kharkiv National University of V. N. Karazin. Prosp. Ak. Kurchatova, 29, Kharkiv, Ukraine, 61108, email: esvoronenko@ gmail.com, ORCID ID: https://orcid.org/0000-0002-9474-198X

\section{НЕЗАВИСИМЫЕ ПРЕДИКТОРЫ ПОЗИТИВНОГО ОТВЕТА НА ИМПЛАНТАЦИЮ ЭЛЕКТРОКАРДИОСТИМУЛЯТОРА У ПАЦИЕНТОВ С ХРОНИЧЕСКОЙ СЕРДЕЧНОЙ НЕДОСТАТОЧНОСТЬЮ}

Бринза М. С., Вороненко О. С.

Введение. В течение последних десятилетий регистрируют увеличение смертности от хронической сердечной недостаточности, для лечения которой может применяться имплантация электрокардиостимулятора. Имплантация ЭКС расширяет возможности медикаментозной терапии, но требует профессионального мониторинга и титрования используемых лекарственных средств.

Цель. Определить и оценить независимые предикторы положительного ответа на имплантацию постоянного электрокардиостимулятора у пациентов с хронической сердечной недостаточностью в зависимости от наличия сахарного диабета 2-го типа.

Материалы и методы. Обследовано 203 больных хронической сердечной недостаточностью, находившихся на стационарном лечении и амбулаторном обследовании в отделении ультразвуковой и клинико-инструментальной диагностики и миниинвазивных вмешательств ГУ «Институт общей и неотложной хирургии им. В. Т. Зайцева НАМН Украины», которые имели обоснованные показания для имплантации электрокардиостимулятора. Имплантация электрокардиостимулятора проведена 102 больным с хронической сердечной недостаточностью с сопутствующим сахарным диабетом 2-го типа, которые составили основную или первую группу; среди представителей этой группы было 52 человека, средний возраст обследованных участников составлял $(67,7 \pm 8,3)$ лет. В качестве контрольной группы выбраны пациенты с хронической сердечной недостаточностью, которым также проведено имплантация ЭКС, но без коморбидной патологии в виде сахарного диабета $(\mathrm{n}=101)$.

Результаты. Установлено, что женский пол достоверно ассоциировался с отсутствием ответа на имплантацию электрокардиостимулятора. В рамках выявленного уровня достоверности установлено влияние режима ЭКС, который был ассоциирован с режимом DDDR и наличием ответа на лечение. Пациенты с атриовентрикулярной блокадой Мобитц II имели достоверно более высокие шансы ответить на имплантацию электрокардиостимулятора. Анализируя клинические формы ишемической болезни сердца, установлено, что по сравнению с пациентами без этой патологии, наличие стабильной 
стенокардии достоверно увеличивала шансы не ответить на имплантацию. Подобное, но более сильное влияние, оказывало наличие кардиосклероза любого генеза.

Выводы. Полученные независимые предикторы позволяют провести раннюю оценку успешности проведения электрокардиостимуляции у пациентов с хронической сердечной недостаточностью, что может предотвратить нежелательные последствия или провести предварительную профилактику с целью улучшения ответа на имплантацию электрокардиостимулятора у таких пациентов.

КЛЮЧЕВЫЕ СЛОВА: хроническая сердечная недостаточность, имплантация электрокардиостимулятора, сахарный диабет 2-го типа

\section{ІНФОРМАЦИЯ ОБ АВТОРАХ}

Брынза Мария Сергеевна, к.мед.н., доцент, заведующая кафедрой пропедевтики внутренней медицины и физической реабилитации Харьковского национального университета имени В. Н. Каразина, проспект Ак. Курчатова, 29, Харьков, Украина, 61108, e-mail: maltsevamariya@ gmail.com, ORCID ID: https://orcid.org/0000-00029474-198X

Вороненко Елена Сергеевна, ассистент кафедры пропедевтики внутренней медицины и физической реабилитации Харьковского национального университета имени В. Н. Каразина, проспект Ак. Курчатова, 29, Харьков, Украина, 61108, e-mail: esvoronenko@gmail.com, ORCID ID: https://orcid.org/0000-0002-9474-198X

Отримано: 20.11.2020 p. Прийнато до друку: 12.01.2021 p. 